\title{
Penurunan Daya Beli Di Indonesia Periode 2012 - 2017 Dan Dampaknya Terhadap Harga Saham Perusahaan Ritel Go Publik
}

\author{
Erni Prasetiyani ${ }^{1)}$, Sukarni Novitasari ${ }^{2)}$ \\ Institut Ilmu Sosial dan Manajemen Stiami \\ Email : 1 erasetiya@gmail.com,2sari_buanapersadatama@yahoo.com
}

\begin{tabular}{ll}
\hline ARTICLE INFO & ABSTRACT \\
\hline Keywords: & $\begin{array}{l}\text { Declining purchasing power in several retail outlets that occurred in } 2017 \text { indicates a } \\
\text { change in consumer behavior. This study discusses an indication of a decrease in } \\
\text { purchasing power and its effect on stock prices in } 6 \text { retail companies that have go } \\
\text { Buy Power, } \\
\text { Retail, }\end{array}$ www.idx.co.id using financial statement analysis using the ratio of Total Asset Turn \\
Go Public, & Over (TATO), Return on Equity (ROE), Return on Investment (ROI), Inventory Turn \\
Shares. & Over (ITO), Average Day Inventory (ADI) as independent variables and Market to \\
& Book Value (MBV) as the dependent variable. Data is processed using Linear \\
& Regression Data Panel. The results of the hypotheses of the five ratios which are made \\
as independent variables are only TATO, ROE and ROI which partially affect MBV.
\end{tabular}

\section{PENDAHULUAN}

Tahun 2017 diwarnai dengan banyaknya ritel skala nasional yang menutup gerainya karena pengaruh penurunan daya beli masyarakat. Sejak 3 tahun lalu pengusaha ritel sudah mulai merasakan dampak dari penurunan daya beli masyarakat yang berakibat pada penurunan profit yang cukup signifikan terhadap keuangan perusahaan. Penurunan daya beli masyarakat terhadap barang-barang konsumsi dianalisa oleh beberapa pengamat ekonomi Faisal Basri, Liputan6.com (10 Oktober 2017) terjadi karena beralihnya perilaku masyarakat. Berikut beberapa perubahan perilaku masyarakat : a). Perubahan perilaku ke konsumsi leisure, b). Perubahan prioritas dari konsumsi ke investasi, c). Turunnya daya beli pada kelas menengah ke bawah, dan d). Pergeseran dari belanja offline ke belanja online.

Dari fenomena ini mengakibatkan beberapa department store menutup gerainya dibeberapa daerah, berikut data yang diambil dari www.cermati.com Matahari Department Store menutup 3 gerai, Ramayana Department Store 8 gerai, Lotus Department Store 2 gerai, Debenhams Department Store 2 gerai, Hero Supermarket 74 gerai sejak 2015 - 2017, Sevel (7-Eleven) menutup seluruh gerai, dan Hypermart 2 gerai.

Rumusan masalah penelitian terdiri dari : a). Seberapa besar pengaruh perubahan perilaku masyarakat terhadap penurunan penjualan perusahaan ritel?, b). Apakah terdapat keterkaitan penutupan gerai ritel akibat penurunan daya beli terhadap fluktuasi harga saham perusahaan ritel terbuka (Tbk)?, dan c). Bagaimana mengantisipasi perubahan perilaku masyarakat, agar perusahaan tetap memperoleh kinerja keuangan yang baik dimasa yang akan datang?

\section{TINJAUAN PUSTAKA}

\section{Daya Beli}

Daya beli menurut pengertiannya adalah kemampuan masyarakat sebagai konsumen untuk membeli barang atau jasa yang dibutuhkan, daya beli masyarakat ini ditandai dengan adanya kenaikan ataupun penurunan, dimana daya beli naik jika lebih tinggi dibanding periode lalu sedangkan daya beli menurun ditandai dengan lebih tingginya kemampuan beli masyarakat dari pada periode sebelumnya.

Faktor-faktor yang mempengaruhi daya beli masyarakat antara lain : a). Tingkat Pendapatan, b). Tingkat Pendidikan, c). Tingkat Kebutuhan, d). Kebiasaan Masyarakat, e). Harga Barang, f). Mode dan Trend, 


\section{Harga Saham}

Saham adalah satuan nilai atau pembukuan dalam berbagai instrumen finansial yang mengacu pada bagian kepemilikan sebuah perusahaan. Dengan menerbitkan saham, memungkinkan perusahaan-perusahaan yang membutuhkan pendanaan jangka panjang untuk 'menjual' kepentingan dalam bisnis - saham (efek ekuitas) - dengan imbalan uang tunai. Saham dijual melalui pasar primer (primary market) atau pasar sekunder (secondary market).

Dan menurut (Kieso, 2007), setiap kepentingan pemilik perusahaan diwakili oleh jumlah lembar saham yang dimiliki dan setiap saham memiliki hak dan keistimewaan atau privilege tertentu yang hanya dapat dibatasi oleh kontrak khusus pada saat saham diterbitkan. Jika tidak ada yang membatasi, maka setiap saham memiliki hak-hak berikut : a). Untuk membagi laba dan rugi secara proporsional, b). Untuk ikut serta dalam manajemen (hak untuk memilih direktur) secara proporsional, c). Untuk membagi asset perusahaan bila terjadi likuidasi secara proporsional, dan d). Untuk ikut serta secara proporsional dalam setiap penerbitan saham baru dari kelompok yang sama, disebut hak istimewa (preemptive right).

Menurut (Halim A. , 2009), saham merupakan klaim paling akhir urutannya atau haknya. Bila perusahaan mengalami kebangkrutan, maka kas yang ada dipakai untuk melunasi utang terlebih dahulu, baru kemudian jika terdapat sisa, kas tersebut digunakan untuk membayar pemegang saham.

Harga saham adalah harga saham di bursa saham pada saat tertentu yang ditentukan oleh pelaku pasar baik permintaan maupun penawaran saham yang bersangkutan di pasar modal.

Permintaan saham dipengaruhi oleh banyaknya investor yang ingin berpartisipasi memiliki saham pada sebuah perusahaan pada saat go publik. Sedangkan penawaran dalam perdagangan saham dipengarui oleh harga dan lembar saham saat emiten mengeluarkan saham pada saat Initial Public Offering (IPO) atau penawaran perdana saham dilantai bursa efek kepada masyarakan atau investor baik secara institusi maupun secara perorangan. Setelah IPO dilakukan maka saham akan memasuki fase perdagangan pasar sekunder (secondery market) yaitu perdagangan saham pada bursa saham setelah penawaran perdana dilakukan. Tinggi atau turunnya permintaan dan tinggi atau turunnya penawaran akan mempengaruhi harga saham. Berikut faktor-faktor yang mempengaruhi harga saham pada pasar sekunder, menurut portal www.cermati.com, diedit oleh Boby Chandro Oktavianus :

\section{Aksi Korporasi Perusahaan}

Aksi korporasi yang dimaksud di sini yaitu upaya merubah kondisi fundamental perusahaan yang bertujuan untuk kemajuan bisnis dimasa mendatang. Perubahan ini dilakukan dengan melakukan kajian terlebih dahulu oleh konsultan yang berkompeten dibidangnya untuk mengetahui efek jangka pendek dan jangka panjang bagi perusahaan. Contoh dari aksi korporasi adalah terjadinya akuisisi, merger, right issue, atau divestasi.

\section{Proyeksi Kinerja Perusahaan pada Masa Mendatang}

Laporan keuangan yang diterbitkan setiap kuartal merupakan performa/kinerja perusahaan menjadi salah satu yang turut memengaruhi fluktuasi harga saham. Performa perusahaan dijadikan acuan bagi para investor maupun analis fundamental dalam melakukan pengkajian terhadap saham perusahaan. Di antara beberapa faktor, yang paling menjadi sorotan adalah tingkat dividen tunai, tingkat rasio utang, rasio nilai buku/Price to Book Value (PBV), earnings per share (EPS), dan tingkat laba suatu perusahaann. Perusahaan yang menawarkan dividend payout ratio (DPR) yang lebih besar cenderung disukai investor karena bisa memberikan imbal balik yang bagus.

\section{Kebijakan Pemerintah}

Kebijakan Pemerintah juga dapat memengaruhi harga saham meskipun kebijakan itu masih dalam tahap wacana dan belum terealisasi. Banyak contoh dari kebijakan Pemerintah yang menimbulkan volatilitas harga saham, seperti kebijakan ekspor impor, kebijakan perseroan, kebijakan utang, kebijakan Penanaman Modal Asing (PMA), dan lain sebagainya. 


\section{Fluktuasi Kurs Rupiah terhadap Mata Uang Asing}

Kuat ataupun lemahnya kurs rupiah terhadap mata uang asing sering kali menjadi penyebab naik turunnya harga saham di bursa. Konsekuensi dari fluktuasi kurs tersebut bisa berdampak positif ataupun negatif bagi perusahaan-perusahaan tertentu, khususnya yang memiliki beban utang mata uang asing. Perusahaan importir atau perusahaan yang memiliki beban utang mata uang asing akan dirugikan akibat melemahnya kurs.

\section{Kondisi Fundamental Ekonomi Makro}

Kondisi fundamental ekonomi makro juga memiliki dampak langsung terhadap naik dan turunnya harga saham, misalnya: a). Naik atau turunnya suku bunga yang diakibatkan kebijakan bank sentral Amerika (Federal Reserve), b). Naik atau turunnya suku bunga acuan Bank Indonesia (BI) dan nilai ekspor impor yang berakibat langsung pada nilai tukar rupiah terhadap dolar AS, c). Tingkat inflasi juga termasuk dalam salah satu faktor kondisi ekonomi makro, dan d). Pengangguran yang tinggi yang diakibatkan faktor keamanan dan goncangan politik juga berpengaruh secara langsung terhadap naik atau turunnya harga saham.

\section{Rumor dan Sentimen Pasar}

Pasar saham ini sangat rawan akan info-info manipulatif, berita, ataupun rumor. Sekadar isu saja yang entah darimana sumbernya bisa saja berpengaruh terhadap kenaikan atau penurunan harga saham.

\section{Faktor Manipulasi Pasar}

Manipulasi pasar saham juga kerap terjadi dan bisa secara langsung berdampak pada naik atau turunnya harga saham. Manipulasi pasar biasanya dilakukan investor-investor berpengalaman dan bermodal besar dengan memanfaatkan media massa untuk memanipulasi kondisi tertentu demi tujuan mereka, baik menurunkan maupun meningkatkan harga saham.

\section{Faktor Kepanikan}

Faktor kepanikan ini juga bisa secara langsung berefek pada fluktuasi harga saham. Ambil contoh kasus pada tahun 2006, sewaktu muncul pemberitaan di media massa tentang meledaknya salah satu pipa milik Perusahaan Gas Negara (PGN) akibat lumpur Lapindo. Munculnya berita tersebut berdampak langsung pada harga saham PGN yang memiliki kode saham PGAS.

Tujuan penelitian ini untuk : a). Mengukur penurunan daya beli terhadap harga saham di lantai Bursa Efek Indonesia, b). Memberikan informasi kepada kepada pemegang saham tentang ada atau tidaknya keterkaitan pengumuman penutupan gerai ritel terhadap fluktuasi harga saham, dan c). Perusahaan mampu membaca perubahan pasar dengan cepat sebagai strategi untuk antisipasi dan mempertahankan kinerja keuangan yang baik dimasa yang akan datang.

\section{METODE PENELITIAN}

Data penelitian merupakan data sekunder dan jenis data yang dikumpulkan adalah data cross section dan data time series. Berdasarkan jenis penelitian dari data yang dikumpulkan maka penelitian ini merupakan penelitian kuantitatif. Menurut (Burns N, 2005) dalam terjemahan penelitian kuantitatif adalah proses formal dan objektif, sistematis dimana data numerik digunakan untuk memperoleh informasi tentang dunia.

Metode penelitian ini digunakan untuk: a). menggambarkan variabel, b). memeriksa hubungan antar variabel, dan c). menentukan interaksi sebab-akibat antara variabel.

Teknik pengumpulan data kuantitatif yang akan dilakukan adalah dengan eksplorasi sumber internet yang berasal dari website bursa atau www.idx.co.id, baik berupa data laporan keuangan audit maupun data index harga saham perusahaan ritel pada periode 2012 sampai dengan 2017. Beberapa data menggunakan sumber data dari Bursa Efek Indonesia (BEI), website penyedia data keuangan perusahaan go public.

Untuk mengukur penurunan daya beli perusahaan, peneliti mengolah data sekunder dengan menggunakan beberapa analisa rasio diantaranya : 


\begin{tabular}{|c|c|c|c|c|}
\hline No & Nama Variabel & Konsep & Formula & Skala \\
\hline 1 & $\begin{array}{l}\text { Market to Book } \\
\text { Value (Y) }\end{array}$ & $\begin{array}{lr}\text { Menunjukkan penilaian pasar } \\
\text { terhadap manajemen } \\
\text { organisasi dari perusahaan }\end{array}$ & $\begin{array}{l}\text { Harga pasar per lembar } \\
\text { saham } \\
\begin{array}{l}\text { Nilai Buku perlembar } \\
\text { saham }\end{array}\end{array}$ & Rasio \\
\hline 2 & $\begin{array}{l}\text { Total Assets Turn } \\
\text { Over/TATO }\end{array}$ & $\begin{array}{l}\text { Rasio perputaran total aktiva } \\
\text { yang menunjukkan efektifitas } \\
\text { perusahaan menggunakan } \\
\text { keseluruhan aktiva untuk } \\
\text { menciptakan penjualan dan } \\
\text { mendapatkan laba }\end{array}$ & $\frac{\text { Net Sales }}{\text { Total Assets }}$ & Rasio \\
\hline 3 & $\begin{array}{l}\text { Inventory } \\
\text { Over/ITO }\end{array}$ & $\begin{array}{l}\text { Rasio perputaran persediaan } \\
\text { digunakan untuk mengukur } \\
\text { efektifitas dan efisensi dana } \\
\text { yang tertanam dalam persediaan. }\end{array}$ & $\begin{array}{l}\text { Cost of Good Sold } \\
\text { Average Inventory }\end{array}$ & Rasio \\
\hline 4 & $\begin{array}{l}\text { Average Day } \\
\text { Inventory/ADI }\end{array}$ & $\begin{array}{llr}\text { Waktu/ lama rata-rata } \\
\text { persediaan tersimpan } \\
\text { gudang sebelum terjual }\end{array}$ & $\frac{360 \text { days }}{\text { Inventory Turn Over }}$ & Rasio \\
\hline 5 & $\begin{array}{l}\text { Return } \\
\text { Equity/ROE }\end{array}$ & $\begin{array}{l}\text { Kemampuan perusahaan yang } \\
\text { berasal dari modal sendiri untuk } \\
\text { menghasilkan laba bersih }\end{array}$ & $\begin{array}{l}\text { Earning After Tax } \\
\text { Equity }\end{array}$ & Rasio \\
\hline 6 & $\begin{array}{l}\text { Return on } \\
\text { Investment/ROI }\end{array}$ & $\begin{array}{l}\text { Kemampuan perusahaan } \\
\text { menghasilkan laba bersih dari } \\
\text { aset yang digunakan. }\end{array}$ & $\begin{array}{l}\text { Earning After Tax } \\
\text { Total Assets }\end{array}$ & Rasio \\
\hline
\end{tabular}

Teknik pengolahan data adalah dengan menggunakan program Econometric Views 9 (Eviews). Dari data variable yang peneliti menguji variable tersebut dengan model regresi data panel. Analisa Korelasi. Terdapat tiga jenis teknik estimasi model regresi data panel, yaitu common effect model, fixed effect model dan random effect model. Sebagai berikut : a). Common Effect Model, Model ini adalah pendugaan yang menggabungkan (pooled) seluruh data time series dan cross section dan menggunakan pendekatan OLS (Ordinari Least Square) untuk menduga parameternya. Metode OLS salah satu metode popular untuk menduga nilai parameter dalam persamaan regresi linier (Baltagi, 2005). Pendekatan Pooled Least Square (PLS) secara sederhana menggabungkan (pooled) seluruh data time series dan cross section dan kemudian mengestimasi model dengan menggunakan metode ordinary least square (OLS), b). Fixed Effect Model, dan c). Random Effect Model.

Uji Pemilihan Model terdiri dari : a). Uji F-Chow/F-Test, dan b). Uji Hausman. Uji Asumsi Klasik Terdiri dari : a). Uji Autokorelasi, b). Uji Normalitas, c). Uji Heteroskedastisitas, dan d). Uji Multikolinieritas

\section{HASIL PENELITIAN DAN PEMBAHASAN}

\section{Analisis Deskriptif}

Jenis data yang digunakan dalam penelitian ini adalah berupa data panel, yakni gabungan antara data runtut waktu (time series) dan data silang (cross section). Data runtut waktu (time series) tahunan untuk periode 2012 sampai dengan 2017. Data silang (cross section) meliputi enam perusahaan ritel yang menerbitkan laporan keuangan, yakni PT Matahari Department Store, Tbk, PT Hero Supermarket, Tbk, PT Ramayana Lestari Sentosa, Tbk, PT Mitra Adiperkasa, Tbk, PT Modern Internasional, Tbk dan PT Matahari Putra Prima, Tbk. Berdasarkan ketersediaan data dari laporan tahunan tersebut sebanyak 36 data maka data tersebut dianggap telah representatif. 
Dibawah ini adalah deskripsi data yang digunakan dalam penelitiaan ini yang telah diolah dengan menggunakan eviews.

\section{Hasil Uji Analisis Deskriptif}

Rata-rata MBV selama periode penelitian tahun 2012 hingga 2017 adalah sebesar 33,42, dengan nilai minimum 0,50 dan maksimum 132,33, memiliki standar deviasi sebesar 34,70.

Rata-rata TATO selama periode penelitian tahun 2012 hingga 2017 adalah sebesar 1,50, dengan nilai minimum 0,26 dan maksimum 2,33, memiliki standar deviasi sebesar 0,58.

Rata-rata ROE selama periode penelitian tahun 2012 hingga 2017 adalah sebesar 0,14, dengan nilai minimum -1,47 dan maksimum 3,02, memiliki standar deviasi sebesar 0,76.

Rata-rata ROI selama periode penelitian tahun 2012 hingga 2017 adalah sebesar 0,02, dengan nilai minimum $-1,22$ dan maksimum 0,39, memiliki standar deviasi sebesar 0,24.

Rata-rata ADI selama periode penelitian tahun 2012 hingga 2017 adalah sebesar 4,04, dengan nilai minimum 1,46 dan maksimum 7,31, memiliki standar deviasi sebesar 44,20.

Rata-rata ITO selama periode penelitian tahun 2012 hingga 2017 adalah sebesar 33,42, dengan nilai minimum 0,50 dan maksimum 132,33, memiliki standar deviasi sebesar 1,33.

\section{Analisis Korelasi}

Berdasarkan output Hasil Uji Analisis Korelasi, dapat diketahui bahwa antara variabel TATO dengan variabel ROI terdapat korelasi linier lemah $(0,496)$. Antara variabel TATO dengan variabel ROE terdapat korelasi linier yang lemah $(-0,074)$. Antara variabel TATO dengan variabel ITO terdapat korelasi linier yang lemah $(0,094)$. Demikian pula antara Variabel TATO dengan variabel ADI terdapat korelasi linier yang lemah $(-0,132)$, atau bahkan mendekati tidak adanya hubungan linier (nilai koefisien korelasi mendekati nol).

\section{Pemilihan Teknik Estimasi Regresi Data Panel}

Hasil pengujian common effect dengan software olahdata eviews versi 9, bahwa variabel bebas TATO dan ROE (t-test probability) signifikan dengan koefisien individual yang memiliki tanda positif diluar variabel individual ADI dan ITO yang memiliki tanda negatif. Hasil Adjusted $\mathrm{R}^{2}$ dari metode ini sebesar 0,568683 dengan nilai Durbin-Watson test sebesar 1,025963 yang rendah (jauh dari range angka 2) yang mengindikasikan adanya autokorelasi. Metode ini mengasumsikan bahwa nilai intersep antar individual dianggap sama yang mana merupakan asumsi yang sangat membatasi (restricted) (Gujarati, 2004:641). Sehingga metode pooled regression ini tidak dapat menangkap gambaran yang sebenarnya atas hubungan yang terjadi antara variabel bebas dengan variabel terikatnya, begitu pula hubungan diantara masing-masing individual cross section.

Hasil pengujian fixed effect dengan software olahdata eviews versi 9, memperlihatkan bahwa jumlah variabel individu atas uji $t$-stat hanya TATO, ROE dan ROI yang memberikan hasil signifikan. Namun nilai adjusted $\mathrm{R}^{2}$ sebesar 0.752528 memberikan nilai tinggi yang cukup memuaskan. Nilai probability dari $f$-stat senilai 0.000000 memberikan artian bahwa model tersebut highly significant dengan nilai Durbin-Watson stat sebesar 1,675042 telah berada pada range angka 2 .

Hasil pengujian random effect dengan software olahdata eviews versi 9, bahwa uji t-stat untuk masing-masing individu memperlihatkan signifikasi sebanyak 2 buah, yaitu variabel TATO dan ROE. Namun nilai adjusted $\mathrm{R}^{2}$ memperlihatkan angka yang cukup yaitu sebesar 0.568683 dan nilai DurbinWatson stat sebesar 1,025963 memberikan angka yang jauh dari kisaran range angka 2 . hal ini juga belum dapat memberikan kepastian metode mana sebaiknya yang digunakan. Maka langkah selanjutnya ialah pengujian pemilihan model.

\section{Uji Pemilihan Model}

Berdasarkan Uji F-Chow/F-Test bahwa nilai Prob. Cross-section F sebesar 0,0135 yang nilainya lebih kecil 0,05 sehingga dapat disimpulkan bahwa model fixed effect lebih tepat dibandingkan dengan model common effect. 
Berdasarkan Uji Hausman terlihat bahwa nilai Prob. Cross-section random sebesar 1 yang nilainya lebih besar dari 0,05 sehingga dapat disimpulkan bahwa model fixed effect lebih tepat dibandingkan dengan model random effect.

\section{Uji Asumsi Klasik}

Berdasarkan output uji autokorelasi didapati nilai Durbin-Watson stat sebesar 1,675042 (Tabel 5). Nilai lebih besar dari DL 1,54 dan lebih kecil dari DU 2,46. Yang berarti tidak ada gejala autokorelasi.

Uji normalitas pada model regresi digunakan untuk menguji apakah nilai residual terdistribusi secara normal atau tidak. Model regresi yang baik adalah yang memiliki nilai residual yang terdistribusi secara normal. Residual dikatakan memiliki distribusi normal jika Jarque Bera > Chi square atau probabilita (pvalue) $>\alpha=5 \%$. Kriteria pengujiannya adalah:

1) $\mathrm{H}_{0}$ : Jarque-Bera $>$ Chi square, $\mathrm{p}$-value $<5 \%$, data tidak terdistribusi dengan normal.

2) $\mathrm{H}_{\mathrm{a}}$ : Jarque-Bera $<$ Chi square, $\mathrm{p}$-value $>5 \%$, data terdistribusi dengan normal.

Nilai Prob. JB hitung sebesar 0,442842 > 0,05 sehingga dapat disimpulkan bahwa residual terdistribusi normal yang artinya asumsi klasik tentang kenormalan telah dipenuhi.

Berdasarkan Uji Heteroskedastisitas, diketahui bahwa seluruh variabel bebas yaitu TATO, ROE, ROI, ADI, ITO memiliki nilai signifikansi lebih besar 0.05. maka dapat dikatakan model regresi terbebas dari masalah heteroskedatis.

Berdasarkan Uji Multikolinieritas diketahui bahwa korelasi antar variabel bebas berada dalam kategori lemah sehingga dapat dipurukan bahwa tidak ada gejala multiko antar variabel bebas.

\section{Analisis Regresi Linier Data Panel}

Analisis Regresi Linier Data Panel pada penelitian ini menggunakan metode fixed effects. Pemilihan metode fixed effect sebagai metode analisis data panel pada penelitian ini sebelumnya diuji melalui uji chow dan uji hausman terlebih dahulu, sehingga akhirnya metode fixed effect yang paling tepat untuk menguji data panel pada penelitian ini. Adapun koefisien regresi dengan model fixed effect adalah sebagai berikut:

$\mathrm{MBV}=15.81352+13.86465 * \mathrm{TATO}+12.87776 * \mathrm{ROE}+29.92321 * \mathrm{ROI}-0.015184 *$ ADI $-0.972687 * \mathrm{ITO}$

Berdasarkan model tersebut dapat diketahui bahwa jika tidak ada pengaruh dari variabel TATO, ROE, ROI, ADI dan ITO variabel MBV memiliki koefisien regresi sebesar 15,81352. Setiap kenaikan satu satuan TATO berpengaruh terhadap peningkatan MBV sebesar 13,86465 satuan. Kenaikan satu satuan ROE berpengaruh terhadap peningkatan MBV sebesar 12,87776 satuan. Kenaikan satu satuan ROI berpengaruh terhadap peningkatan MBV sebesar 29,923321 satuan. Kenaikan satu satuan ADI berpengaruh terhadap penurunan MBV sebesar 0,015184 satuan. Dan kenaikan satu satuan ITO berpengaruh terhadap penurunan MBV sebesar 0,972687 satuan.Uji Hipotesis, Adjusted R2, uji F, dan uji t

Hasil uji Koefisien Determinasi (Adjusted $\mathrm{R}^{2}$ ) diketahui bahwa variabel TATO, ROE, ROI, ADI, dan ITO secara bersama-sama memiliki sumbangan pengaruh terhadap MBV sebesar 0,752528 atau 75,25\% (dibulatkan) dan sisanya sebesar 24,75 dipengaruhi faktor lain yang tidak diteliti.

Uji F digunakan untuk mengetahui apakah variabel bebas secara bersama-sama berpengaruh signifikan terhadap variabel bebas. Hipotesis:

$\mathrm{H}_{\mathrm{o}}$ : Tidak terdapat pengaruh TATO, ROE, ROI, ADI, dan ITO secara bersama-sama terhadap MBV.

$\mathrm{H}_{\mathrm{a}}$ : Terdapat pengaruh TATO, ROE, ROI, ADI, dan ITO secara bersama-sama terhadap MBV

Kriteria pengambilan keputusan:

Ho diterima bila $F_{\text {hitung }}=F_{\text {tabel }}$ (Tidak terdapat pengaruh variabel bebas terhadap variabel terikat)

Ho ditolak bila $F_{\text {hitung }}>F_{\text {tabel }}$ (Terdapat pengaruh variabel bebas dengan variabel terikat)

Nilai $\mathrm{F}$ tabel dapat dilihat pada tabel $\mathrm{F}_{\text {statistik }}$ pada df $1=$ jumlah variabel-1 atau 6-1 = 5 dan

df $2=\mathrm{n}-\mathrm{k}-1$ atau 36-5-1 = 30 (k adalah jumlah variabel bebas). Dengan signifikansi 0,05 diperoleh hasil $\mathrm{F}_{\text {table }}=2,53$. 
Variabel TATO, ROE, ROE, ADI dan ITO secara bersama-sama berpengaruh terhadap MBV. Hal ini karena nilai $F_{\text {hitung }}>F_{\text {table }}(11,63>2,53)$ sehingga Ho ditolak, yang berarti bahwa terdapat pengaruh TATO, ROE, ROI, ADI, dan ITO secara bersama-sama terhadap MBV.

Uji $t$ dalam regresi berganda digunakan untuk mengetahui apakah model regresi variabel bebas secara parsial berpengaruh signifikan terhadap variabel terikat.

Hipotesis:

Ho: Tidak terdapat pengaruh TATO, ROE, ROI, ADI, dan ITO secara parsial terhadap MBV

Ha: Terdapat pengaruh TATO, ROE, ROI, ADI, dan ITO secara parsial terhadap MBV

Kriteria pengambilan keputusan:

Ho diterima bila $-t_{\text {hitung }}=-t_{\text {tabel }}$ atau $t_{\text {hitung }}=t_{\text {tabel }}$ (tidak terdapat pengaruh yang signifikan variable bebas terhadap variabel terikat).

Ho ditolak bila $-t_{\text {hitung }}>-t_{\text {tabel }}$ atau $t_{\text {hitung }}>t_{\text {tabel }}$ (terdapat pengaruh yang signifikan variabel bebas terhadap variabel terikat).

Nilai $\mathrm{t}$ table pada $\mathrm{df}=\mathrm{n}-\mathrm{k}-1$ atau 36-5-1 $=30$ ( $\mathrm{k}$ adalah jumlah variable bebas), dengan signifikansi 0,05 dan uji 2 sisi diperoleh hasil $\mathrm{t}$ table $=2,04227 /-2,04227$.

Berikut variable yang secara parsial berpengaruh terhadap MBV dimana variable tersebut bila mengalami peningkatan maka MBV juga meningkat:

- $\quad$ Variabel TATO , $\mathrm{t}_{\text {hitung }}(2,157569)>$ dari $\mathrm{t}_{\text {tabel }}(2,04227)$, Ho ditolak

- Variabel ROE, $\mathrm{t}_{\text {hitung }}(2,948539)>$ dari $\mathrm{t}_{\text {tabel }}(2,04227)$, Ho ditolak

- Variabel ROI, $\mathrm{t}_{\text {hitung }}\left(3,021510>\right.$ dari $\mathrm{t}_{\text {tabel }}(2,04227)$, Ho ditolak

Untuk variable ADI dan ITO secara parsial tidak berpengaruh terhadap MBV karena - $\mathrm{t}_{\text {hitung }}$ lebih kecil dari $-t_{\text {tabel }}(-0,486433<-2,04227)$ untuk ADI dan nilai $-t_{\text {hitung }}$ lebih kecil dari $-t_{\text {tabel }}(-0,316188>-$ 2,04227 ) sehingga pada masing-masing variable ini Ho diterima.

\section{KESIMPULAN}

Penurunan daya beli berpengaruh signifikan terhadap penurunan penjualan perusahaan ritel go public. Berdasarkan rasio profitabilitas ROE dan ROI pada tabel hasil rasio keuangan, seluruh perusahaan yang dianalisa mengalami penurunan sejak tahun 2012 sampai dengan tahun 2017. Dari hasil hipotesis uji t, Variabel TATO, ROE dan ROI secara parsial berpengaruh terhadap MBV. Dengan adanya penurunan profitabilitas dan berakibat adanya penurunan harga saham maka ke enam Perusahaan ini harus mampu menciptakan strategi baru agar tetap bertahan dan mampu melalui tantangan ini.

\section{SARAN}

Perusahaan perlu melakukan terobosan dan strategi baru dengan melihat fakta dari bisnis yang masih bertahan bahkan bisa lebih berkembang, diantaranya membuka lini Bisnis on line, bermain di segmen yang lebih kecil tetapi kuantitas gerai lebih banyak dan bekerjasama dengan UMKM atau menempatkan bisnis pada lokasi yang vital bagi mobilisasi penduduk seperti terminal, stasiun, bandara, pelabuhan dan lainnya.

\section{DAFTAR PUSTAKA}

Asra, A. (2014). Cerdas Menggunakan Statistik. Edisi Perdana. Bogor: IN Media.

Baltagi, B. (2005). Econometric Analysis of Panel Data, 3rd Edition. New York: John Wiley and Sons Inc.

Burns N, G. S. (2005). The Practice of Nursing Research: Conduct, Critique, and Utilization (5th Ed). St. Louis: Elsevier Saunders.

Ghozali, I. (2013). Aplikasi Analisis Multivariate Dengan Program IBM SPSS 21 Edisi 7. Semarang: Badan Penerbit Universitas Diponegoro.

Halim, A. (2009). Analisis Laporan Keuangan Edisi 4. Yogyakarta: UPP STIM YKPN.

Halim, A. d. (2009). Analisis Laporan Keuangan. Edisi 4. Yogyakarta: UPP STIM YKPN.

Kieso, D. E. (2007). Akuntansi Intermediate. Jakarta: Erlangga. 
Pawenang, S. (2016). Modul Perkuliahan Lingkungan Ekonomi Bisnis . Surakarta: Program Pascasarjana, UNIBA.

Sukardi. (2003). Metodologi Penelitian Pendidikan Kompetensi dan Praktiknya. Jakarta: Aksara. www.idnfinancials.com

$\underline{\text { www.indonesia-investment.com }}$ 